\title{
Methodology for Monitoring Aerial Emissions from Highways
}

\author{
Lamiaa Khalid, Shirook Ali, Vahid Mashatan and Benjamin Komisar \\ Sheridan College \\ Brampton, Ontario, Canada \\ shirook.ali@sheridancollege.ca
}

\begin{abstract}
In this paper, we propose a methodology for real-time vehicle emission monitoring near major highways using fixed and mobile sensor units. We use the U.S. Environmental Protection Agency (EPA) Motor Vehicle Emission Simulator (MOVES) to estimate the emission levels of the transportation-related air pollutants such as carbon monoxide, oxides of nitrogen, methane and hydrocarbons. We aim to correlate the collected real-time data and the MOVES simulator output emission levels. Based on the collected data from the deployed sensors, we will further calibrate the output of the MOVES simulator to provide accurate pollutant emission levels for accurate prediction of air quality near major highways.
\end{abstract}

Keywords: Vehicle Emission Monitoring, MOVES model, Air Quality, Sensors.

\section{Introduction}

Transportation is one of the largest sources of air pollutants in Canada. Burning fossil fuels to power vehicles and engines causes emissions of many air pollutants. Air pollutants are responsible for the formation of fine particulate matter, ozone, smog and acid rain [1]. In Ontario, traffic sources contribute significantly to the total amount of pollutants in the atmosphere (up to $80 \%$ in the case of carbon monoxide). Other important transportation-related air pollutants are oxides of nitrogen $\left(\mathrm{NO}_{\mathrm{x}}\right)$, methane $\left(\mathrm{CH}_{4}\right)$ and hydrocarbons $(\mathrm{HCs})$.

Emissions are considered to be one of the major external costs of vehicles. Vehicle emissions commonly refer to the amount of criteria air contaminants released into the atmosphere by one or more transportation vehicles over a specific time period or travelled distance [2]. Vehicle emissions are dependent on a wide range of factors, including vehicle characteristics, fuel characteristics, roadway characteristics and climate. For road vehicles, most of this amount is generated by fuel combustion (vehicle exhaust emissions), fuel evaporation from parked and driven vehicles, reentrainment of road dust, and tire and brake wear.

Reducing air pollutants emissions from the transportation sector has been a global challenge. To evaluate the pollutant emissions of road transportation, vehicle emissions inventory needs to be calculated. It is very difficult to predict quantitatively vehicle emissions from first principles. Therefore, emission predictions are usually based on vehicle emission test results. The U.S. Environmental Protection Agency (EPA) annually tests a cross-section of vehicle models under controlled laboratory conditions. The test data generated on individual vehicles are used in the U.S. EPA emission simulation model Motor Vehicle Emission Simulator (MOVES) [3]. MOVES estimates emissions for on-road and nonroad sources, covers a broad range of pollutants, and enables multiple-scale analysis from fine scale to national emission inventory scale.

Air pollutant concentrations adjacent to major traffic routes are significantly higher than regional background levels [4]. This makes it essential to estimate air pollutant concentrations near major roadways in urban areas. The objective of our project is to develop an emission monitoring methodology that would provide an accurate measure of air pollutants emissions on Ontario highways. We then aim to utilize the assumptions-based modeling simulator MOVES emission outputs to estimate traffic-related emissions when deploying aerial emission monitoring. MOVES simulator can further be used to identify areas of high emissions where the unmanned aerial vehicle needs to be deployed. We further aim to utilize the output emission levels generated by MOVES for the vehicles fleet on and around the considered highway to calculate pollutant concentrations at desired locations using an air dispersion model. Air dispersion models are used to determine how air-borne pollutants disperse in the atmosphere and how their concentration dilutes over distance and time. Using the output from the air dispersion model, we will then develop site-specific emission information. 
The goal of this paper is to estimate the air pollution emission levels of highway traffic within an urban environment based on the state-of-the-science emission modeling system MOVES. The output of the MOVES estimation model is a database of location specific emission levels of select pollutants that can then be analyzed and compared to the accurate real-time pollution emission level measurements obtained from the deployed sensor network.

In this paper, we focus on characterizing emissions for pollutants emitted by both gasoline and diesel engine emissions. We estimate the emission inventories of the air pollutants of interest which are carbon monoxide (CO), nitrogen oxides $\left(\mathrm{NO}_{\mathrm{x}}\right)$, methane $\left(\mathrm{CH}_{4}\right)$ and hydrocarbons $(\mathrm{HCs})$. Since emission levels are affected by a range of factors such as vehicle type, hour of the day, speed, weather conditions and other factors, we estimate the pollutants emission rates for weekdays and weekends, at various hours of the day.

The rest of the paper is organized as follows. We discuss the most relevant related work in section 2 . We describe the methodology used to develop the proposed system model of our emission modelling system in section 3 . We present the simulation results in section 4 and we conclude the paper in section 5.

\section{Related Work}

In [5], the authors developed a mobile air quality monitoring network (MAQUMON) that utilized moving vehicles equipped with sensor nodes to monitor air quality in a large area. Each sensor node consisted of a microcontroller, an onboard Global Positioning System (GPS) unit, and a set of sensors to detect the concentrations of ozone $\left(\mathrm{O}_{3}\right)$, $\mathrm{CO}$, and nitrogen dioxide $\left(\mathrm{NO}_{2}\right)$. The authors in [6] proposed a wireless sensor network-based urban air quality monitoring system that is connected to a GSM system for centralized control by a LabVIEW program that stores sensed data in a database. They implemented the monitoring systems in the city road of Taipei to monitor the CO concentration caused by vehicle emissions.

In [7], an indoor and an outdoor air pollution monitoring architectures based on Wi-Fi were proposed. In this paper, only the indoor one was implemented and tested. Each sensor node consists of several sensors (temperature and relative humidity sensors, $\mathrm{CO}$, methane and solvent vapors sensors) and a Wi-Fi communication link. In order to mitigate the influence factors (temperature and relative humidity) of the gas sensors, a neural network was implemented to obtain the temperature and relative humidity correcting values for the pollutants' concentrations. Sensed data were processed by a PC and published to a customized web page.

The authors in [8] used an on-road emission measurement device to conduct measurements for a freeway and a road segment of 1-1.4 km, with a 3-6\% grade at different constant speeds and different speed profiles, for a light duty test vehicle. They measured second-by-second emissions, fuel consumption, vehicle speed, engine speed, temperature and some more engine characteristics. Their results showed that the best fuel consumption and emission rates are at constant speeds of 60-90 kilometer per hour and that mild acceleration results in higher fuel consumption and emission rates for most emissions, except $\mathrm{CO}$ and $\mathrm{HCs}$ which are highest for aggressive driving.

In [9], the regional municipality of Halton has undertaken airshed modelling to characterize air quality across Halton Region and determine the contribution of different sectors to air quality across the region. The CALPUFF modelling system, which combines pollution emission information with meteorological data, was selected for the Halton Airshed Modelling Study to evaluate the contribution of existing emission sources on air quality.

MOVES sensitivity analysis was performed in [10] and [11]. The authors showed that the MOVES model is very sensitive to vehicle operating speed and that the acceleration, driving behaviour and roadway grade are critical factors in determining the accuracy of the model.

\section{Proposed Methodology}

In this section, we discuss the approach used to develop the overall methodology of our proposed emission modelling system shown in Figure 1. The proposed system model shown in Figure 2 is used to monitor pollutions in real-time using fixed and a mobile sensor unit network. The MOVES simulation model output is initially used to design the sensor network to provide initial data on sensors placement and deployment.

The fixed sensor units (FSU) are used to monitor air pollutants such as $\mathrm{CO}, \mathrm{NO}_{2}, \mathrm{HCs}$, ground level ozone $\left(\mathrm{O}_{3}\right)$ as well as GHGs such as carbon dioxide $\left(\mathrm{CO}_{2}\right)$. They also include combined humidity and pressure sensors. Those emission sensors, along with other necessary equipment, will also be mounted on an Unmanned Aerial Vehicles (UAV) platform forming mobile sensor unit (MSU). The UAV, aircraft with no pilot onboard, is commonly known as a drone and it is in use in several fields such as military, aerial surveillance as well as a remote sensing apparatus. The UAV platform is 
designed by the research team at Sheridan College. Data analysis and processing will occur from the collected data. This data will then be used for comparisons with the estimation-based emissions model MOVES. Real time data will be used to calibrate the output of the MOVES to aid in accurate predictions of air pollutants emission levels as well as GHGs.

In this paper, we focus on the use of MOVES2014a to obtain the emission inventories for an urban free flow highway segment. We use the project scale which is the finest level of modeling in MOVES. We model a highway segment with a relatively stable average speed as a single link. Data on seven-day hourly traffic volume and hourly average speed was obtained from Ministry of Transportation, Ontario (MTO) for two four-lane segments of the ON401, each of length 1.45 $\mathrm{km}$.

We use a combination of vehicle fleet distribution (link source types: passenger cars, light and heavy duty trucks, motorcycles and buses) with fuel type formulation (gasoline or diesel). Based on the vehicle types, link volume, average speed and acceleration, MOVES estimates the selected pollutants emission level produced on each link (grams/hour/link) during weekdays and weekends peak periods. The above presented MOVES project level link analysis is depicted in Figure 3.

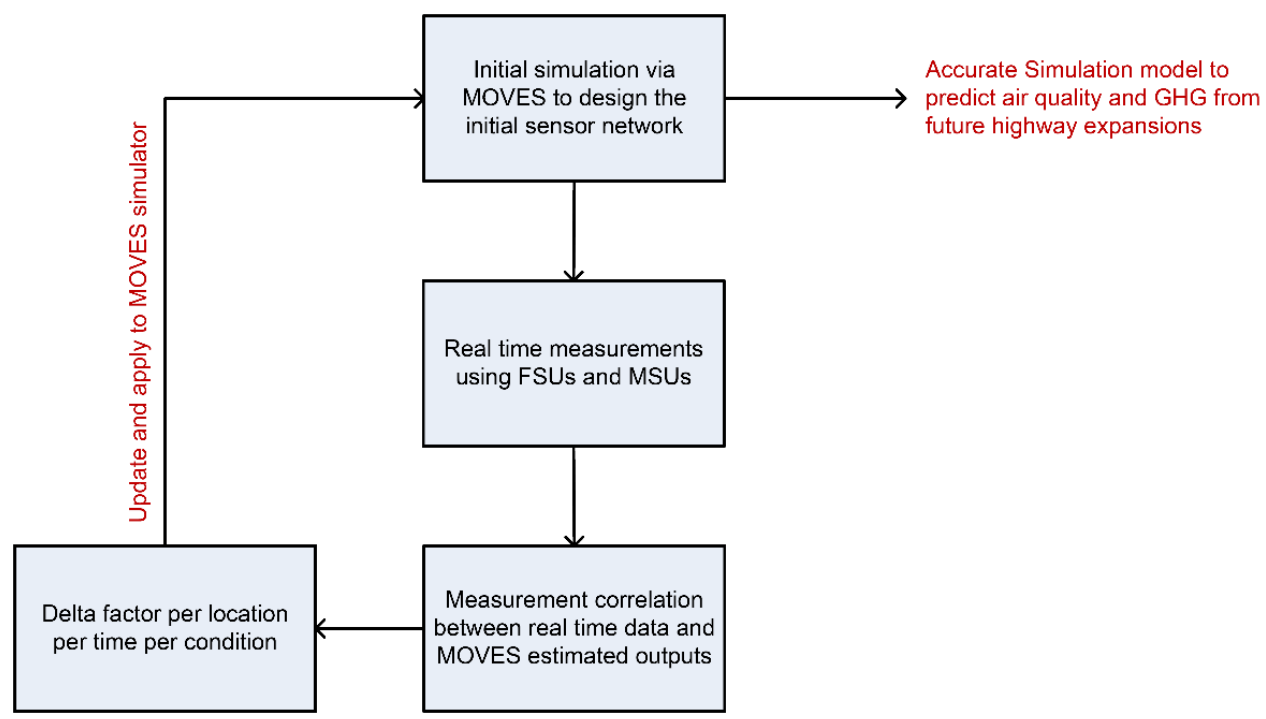

Fig. 1: Overall methodology of the Proposed Emissions Monitoring System.

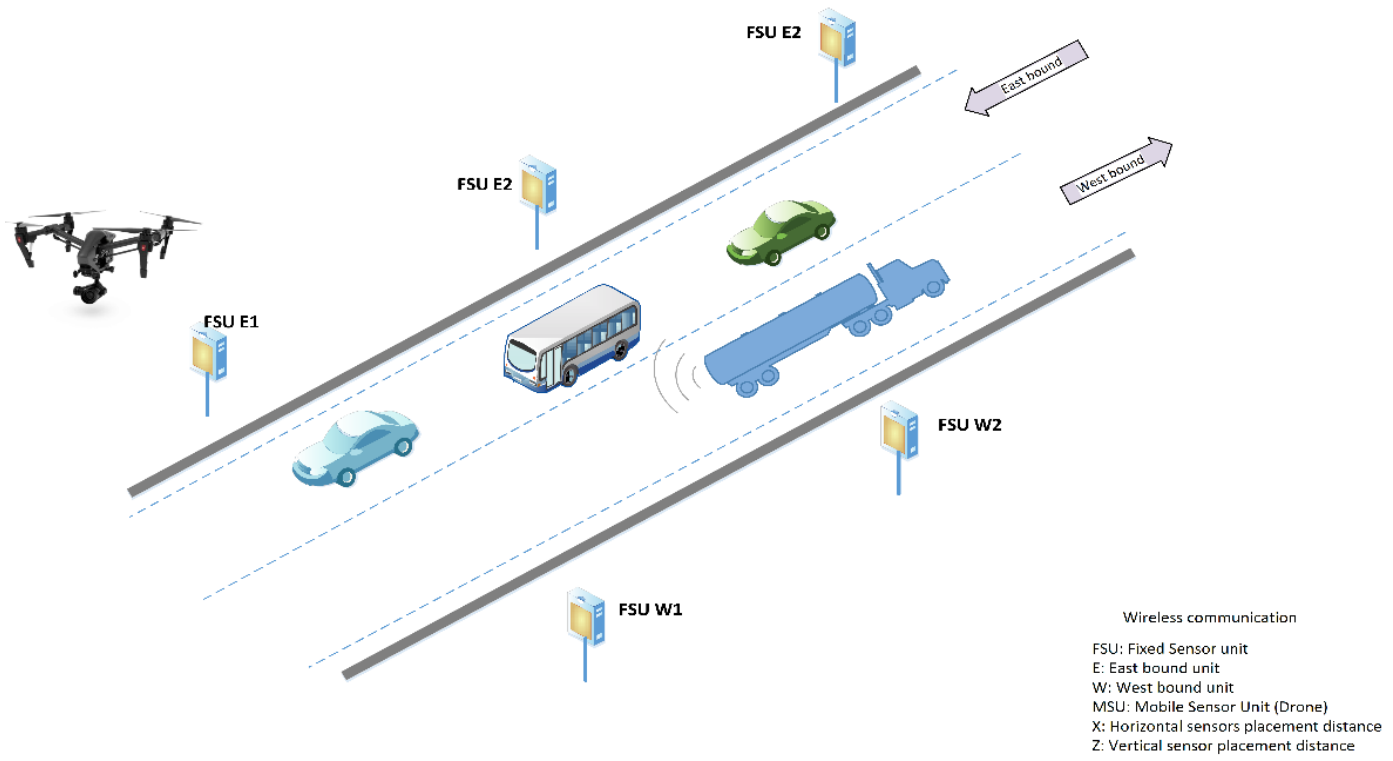

Fig. 2: Proposed System Model with FSUs and MSUs. 


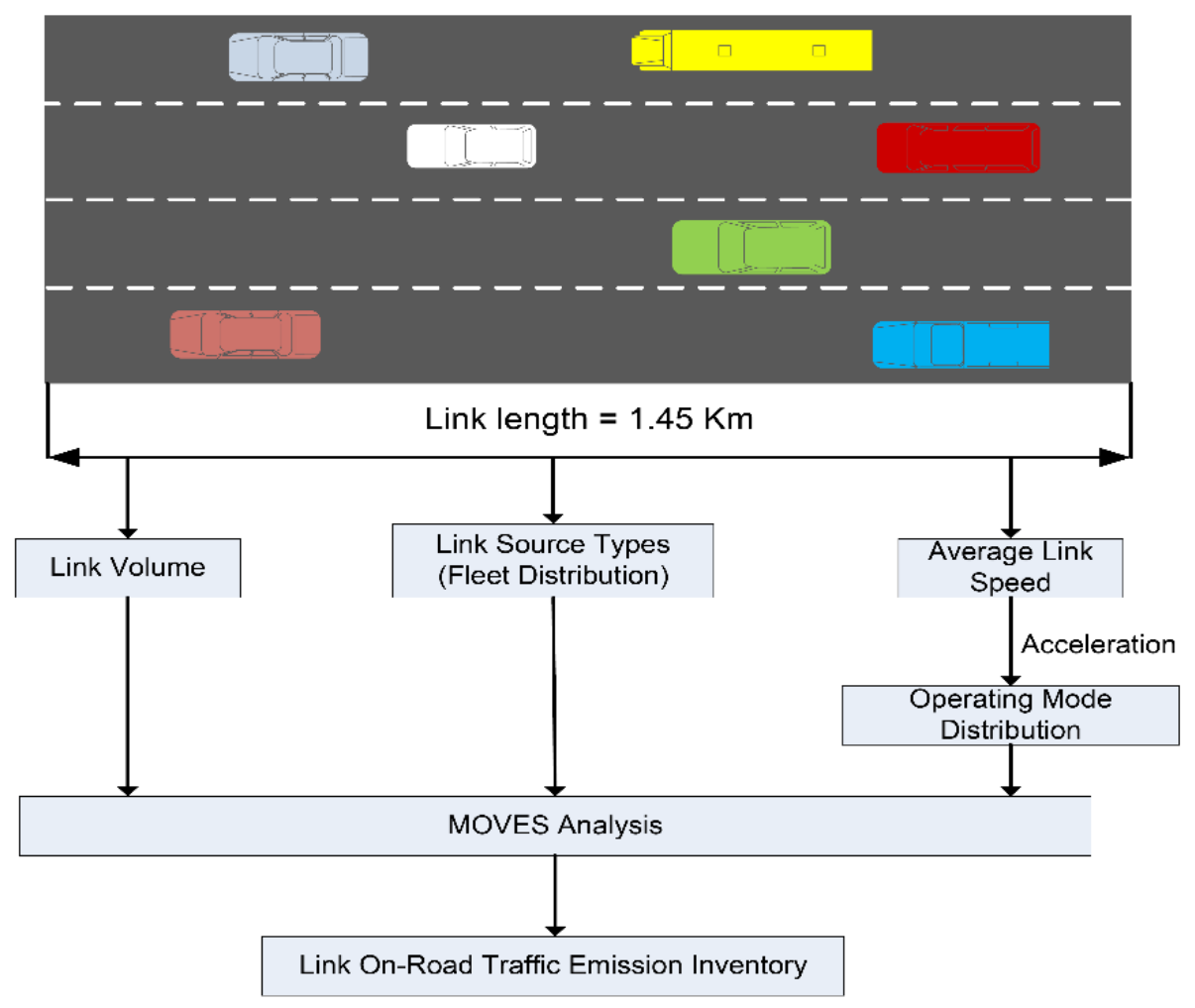

Fig. 3: MOVES Project Level Link Analysis.

\section{Simulation Results}

In this section, we calculate the emission levels using MOVES2014a for two input links with a given average speed, volume and link type information. The results presented in this paper are preliminary and will continue to be refined as the research project progresses.

MOVES model includes detailed information about selecting a substitute county in the US that is closest to Toronto in terms of weather conditions [12]. Simulation runs were conducted with the default MOVES meteorology values for Niagara County, NY, default vehicle age distribution and fuel supply/formulation information provided within the MOVES database. Road grade was assumed to be $0 \%$ (flat route). Runs were conducted at different hours of the day and different days of the week (weekday and weekend) for the month of April. The combination of vehicle fleet distribution (link source types) with fuel type formulation (gasoline or diesel) was obtained from a modelling study for Halton region as shown in Table 1 [9].

We present the emission inventory results from MOVES 2014a for four pollutants: $\mathrm{CO}, \mathrm{NO}_{\mathrm{x}}, \mathrm{HC}$ and $\mathrm{CH}_{4}$. Normalized pollutants emission levels are calculated by dividing each pollutant emission level by the highest pollutant emission level obtained (CO level for weekday at peak hour). By normalizing the pollutants emission levels, the magnitude of the difference between the emission levels of each pollutant is preserved. In addition, since each pollutant is normalized to the same value, we can provide a comparison between the different pollutants emission levels.

Figure 4 shows the normalized $\mathrm{CO}$ emission levels for different days of the week (weekdays and weekend) at different hours of the day (peak and non-peak hours) for different types of diesel and gasoline vehicles as shown in Table 1. From Figure 1, we observe that the CO levels are highest during peak hours (higher traffic volume and lower average speed) and lowest during off peak hours and weekends. This is expected since carbon monoxide emissions increase when conditions are poor for combustion. Since the $\mathrm{CO}$ has the highest emission level among all pollutants considered, the highest value in Figure 4 is 1.

$\mathrm{NO}_{\mathrm{x}}$ emission levels for different days of the week at different hours of the day for different types of vehicles is shown in Figure 5. We observe from the figure that the $\mathrm{NO}_{\mathrm{x}}$ emission levels increase as the link volume increases and the speed 
decreases (weekday peak hour). Since $\mathrm{NO}_{\mathrm{x}}$ is also emitted during fuel combustion, $\mathrm{NO}_{\mathrm{x}}$ emission levels follow the same trend as $\mathrm{CO}$ emission levels but at lower values. The highest emission level of $\mathrm{NO}_{\mathrm{x}}$ is around $20 \%$ lower than the highest $\mathrm{CO}$ emission level (estimated on Monday at $4 \mathrm{PM}$ ). Similar trends are also obtained for $\mathrm{HCs}$ and $\mathrm{CH}_{4}$ emission levels as shown in Figures 6 and 7.

Table 1: Vehicle Fleet Distribution.

\begin{tabular}{|l|l|}
\hline Vehicle Type & Fleet Distribution \\
\hline Light Duty Gasoline Vehicles & $81.17 \%$ \\
\hline Heavy Duty Diesel Trucks & $11.06 \%$ \\
\hline Light Duty Diesel Trucks & $6.45 \%$ \\
\hline Motorcycles (Gasoline) & $1.11 \%$ \\
\hline Diesel Buses & $0.16 \%$ \\
\hline School Buses (Diesel) & $0.05 \%$ \\
\hline
\end{tabular}

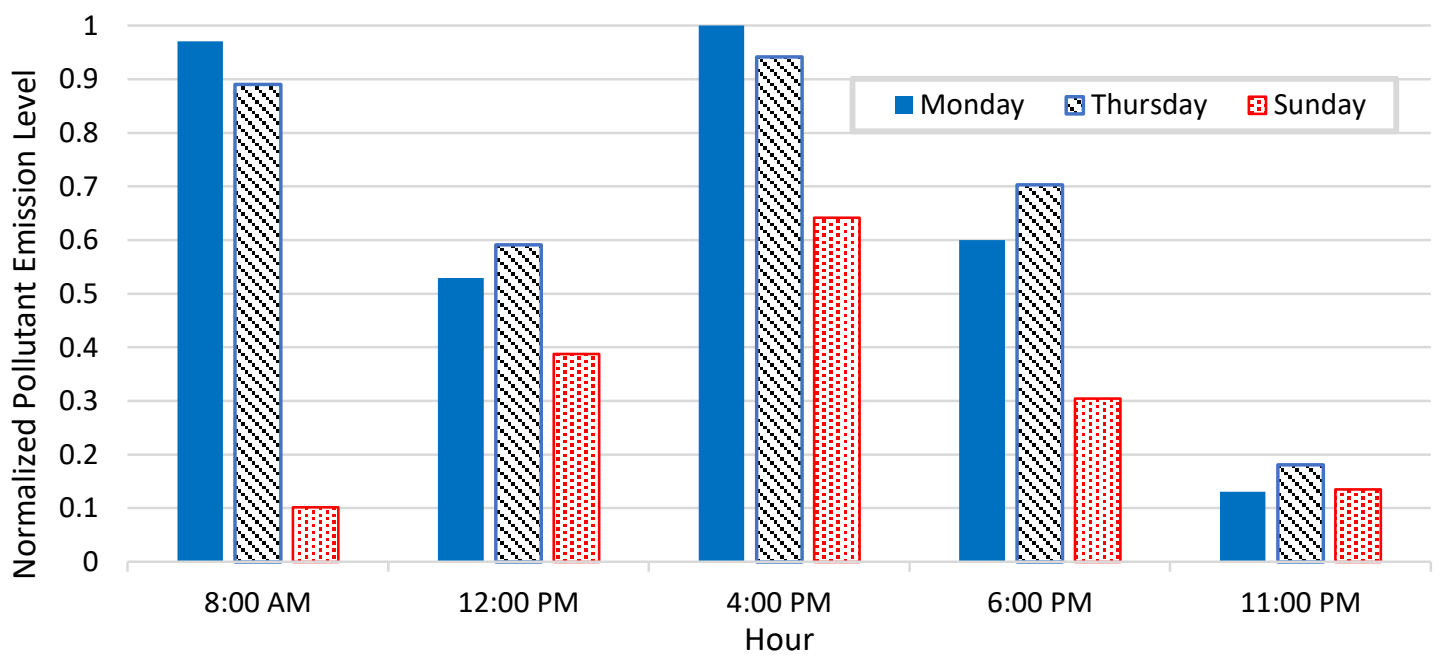

Fig. 4: Normalized CO Emission Levels at Different Hours for Different Week Days.

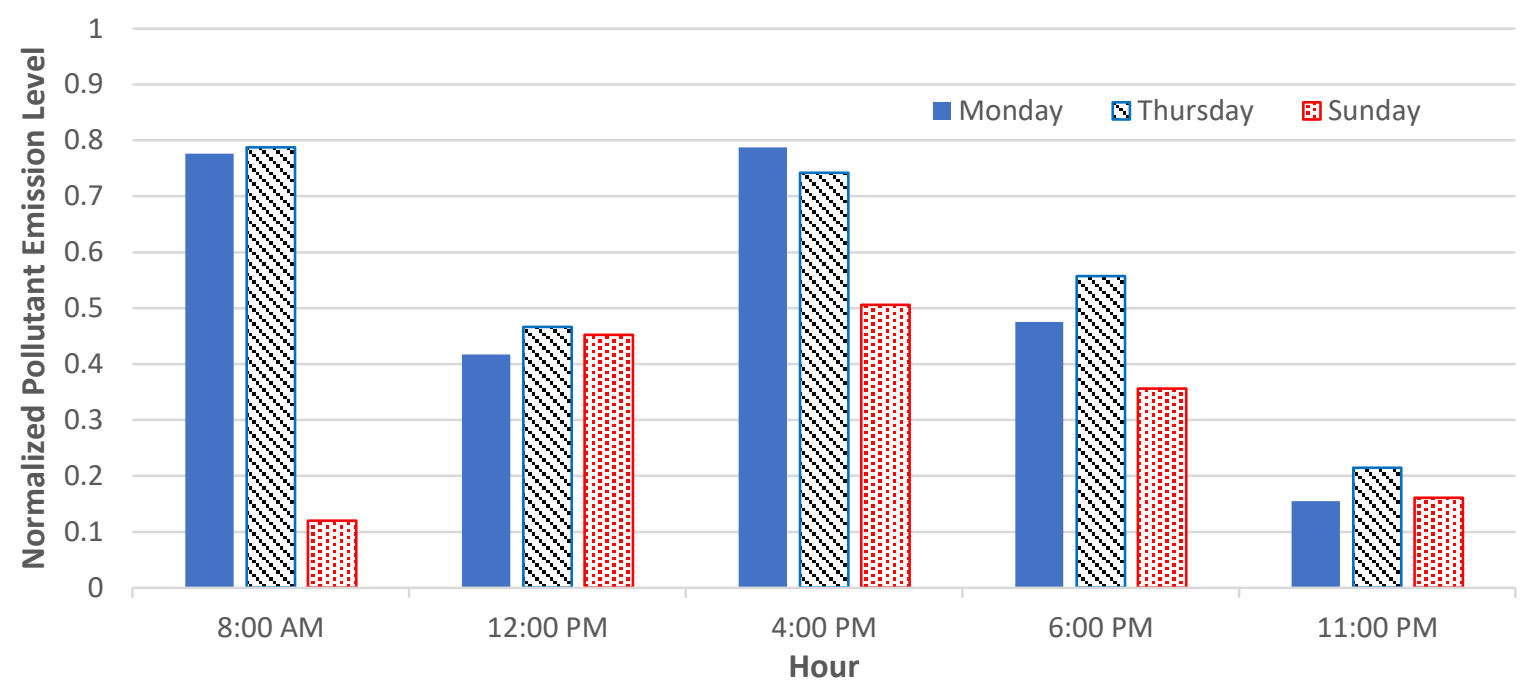

Fig. 5: Normalized $\mathrm{NO}_{\mathrm{x}}$ Emission Levels at Different Hours for Different Week Days. 


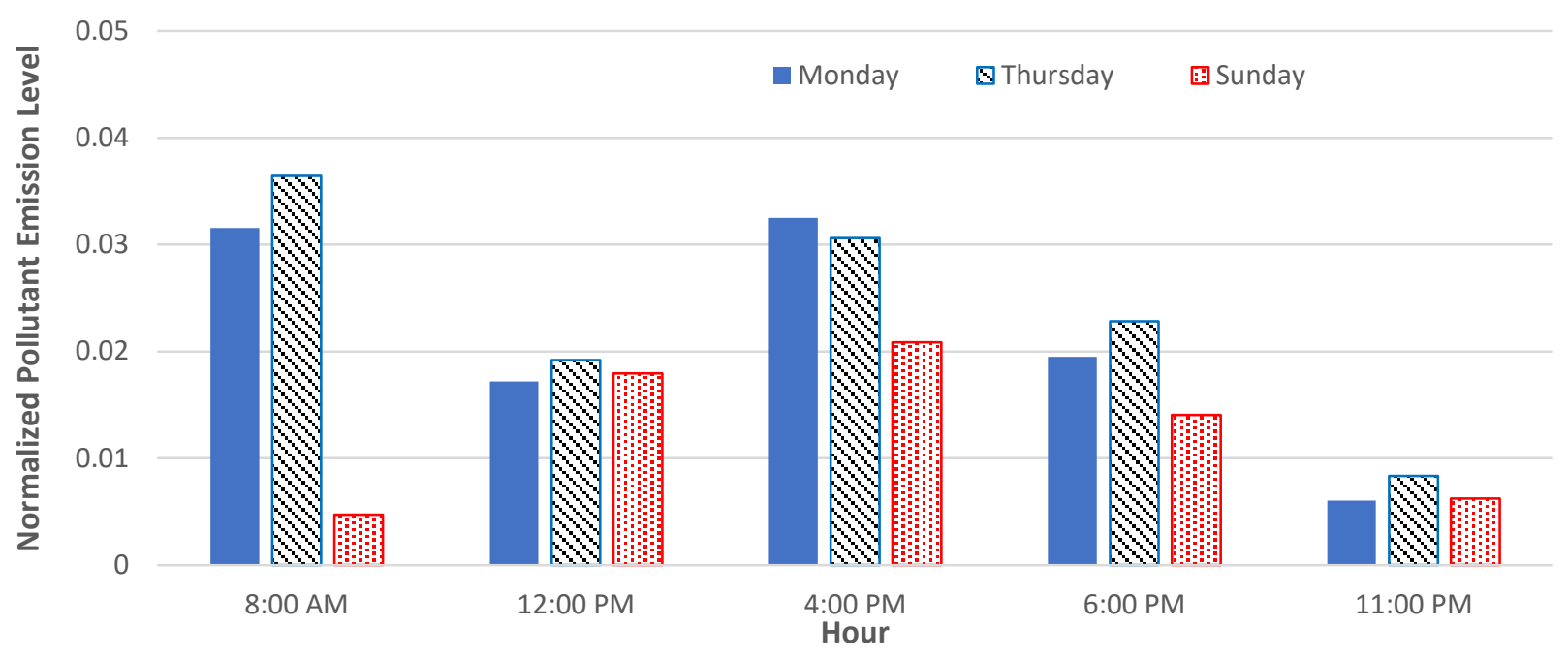

Fig. 6: Normalized HC Emission Levels at Different Hours for Different Week Days.

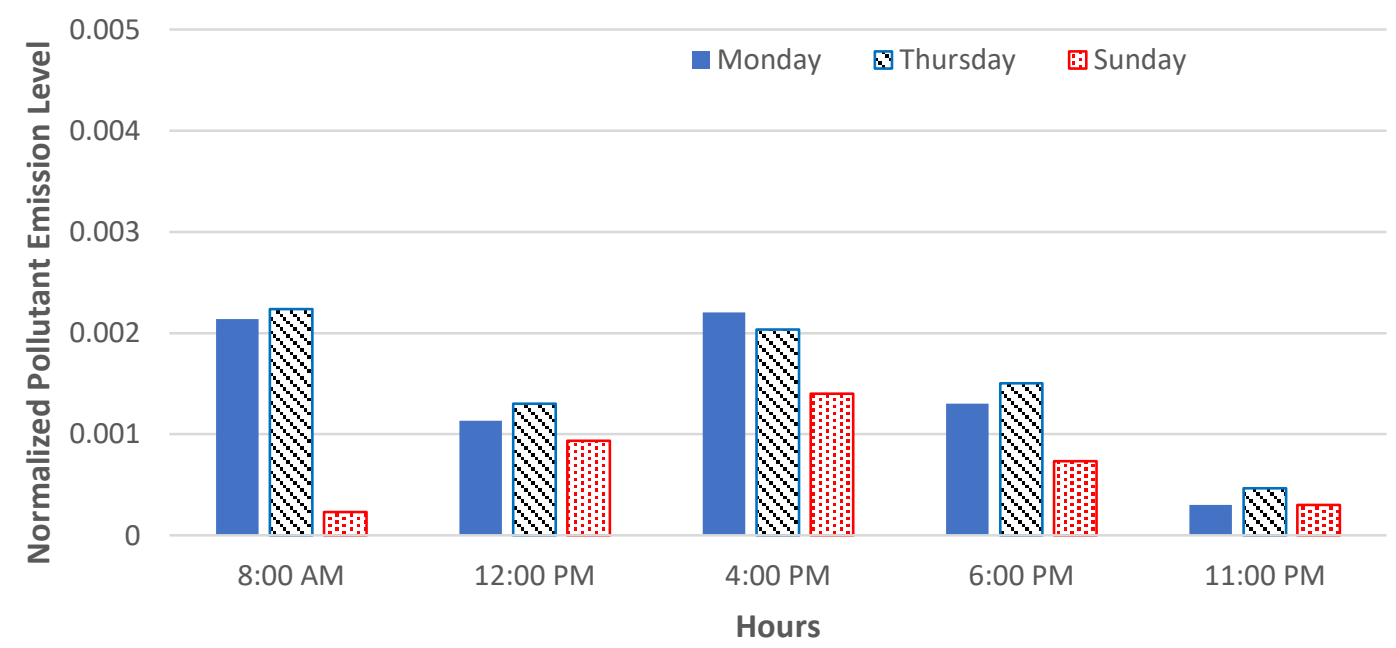

Fig. 7: Normalized $\mathrm{CH}_{4}$ Emission Levels at Different Hours for Different Week Days.

\section{Conclusions}

In this paper, we proposed a methodology that utilizes fixed and mobile sensor units to monitor pollution emission levels in real-time. We initially utilized MOVES emission simulator to estimate the emission levels of different pollutants for the initial design of the proposed sensor network. In this paper, using MOVES, we estimated the emission levels of the air pollutants of interest $\mathrm{CO}, \mathrm{NO}_{\mathrm{x}}, \mathrm{CH}_{4}$ and $\mathrm{HCs}$ for week days, and weekends at different hours of the day to reflect change in temperature and relative humidity, traffic volume and average speed. Simulation results showed the expected ranges of emission levels per hour and the expected ratios of emissions levels between different pollutants. We also obtained the expected trends of emission levels of different pollutants for the weekdays and weekends.

For future work, we aim to utilize the generated MOVES emission levels to calculate pollutant emissions at desired locations using an air dispersion model. Using the output from the air dispersion model, we will develop site-specific emission information. This information will be used to map out the sensor locations (vertical and horizontal placement) for optimal sensor deployment. We will also extend the simulation to include different month (winter and summer month) to account for the change in emission levels for the considered pollutants due to seasonal change. 


\section{Acknowledgements}

This research was supported by a grant from the Ontario Ministry of Transportation (MTO). The authors would like to acknowledge MTO for sponsoring this project and providing the data used in this paper and sharing their valuable experience and insights. Opinions expressed in this report are those of the authors and may not necessarily reflect the views and policies of the ministry.

\section{References}

[1] "Energy Efficiency Trends in Canada 1990 to 2013,” Ministry of Natural Resources, 2016.

[2] "Environmental Guide for Assessing and Mitigating the Air Quality Impacts and Greenhouse Gas Emissions of Provincial Transportation Projects," Ministry of Transportation, 2012.

[3] U.S. Environmental Protection Agency, MOtor Vehicle Emission Simulator (MOVES). [Online]. Available: https://www.epa.gov/moves

[4] S. Samaranayake et al., "Real-time estimation of pollution emissions and dispersion from highway traffic," Computer-Aided Civil and Infrastructure Engineering, vol. 29, pp. 546-558, 2014.

[5] P. Völgyesi, et al. "Air quality monitoring with sensormap," 2008 International Conference on Information Processing in Sensor Networks (ipsn 2008), St. Louis, MO, pp. 529-530, 2008.

[6] J. H. Liu et al. "Developed urban air quality monitoring system based on wireless sensor networks," In Proceedings of the 2011 Fifth International Conference on Sensing Technology (ICST), Palmerston North, New Zealand, 2011, pp. 549-554.

[7] O. A. Postolache, J. M. Dias Pereira and P. M. B. Silva Girao, "Smart Sensors Network for Air Quality Monitoring Applications," IEEE Transactions on Instrumentation and Measurement, vol. 58, no. 9, pp. 3253-3262, 2009.

[8] I. Shawarby, K. Ahn and H. Rakha, "Comparative field evaluation of vehicle cruise speed and acceleration level impacts on hot stabilized emissions," Transportation Research Part D: Transport and Environment, vol. 10, no. 1, pp. 13-30, 2005.

[9] Halton Region, (2010), Executive Summary for Air Quality in Halton: Airshed Modelling Report. [Online]. Available: http://www.halton.ca/cms/One.aspx?portalId=8310\&pageId=61437

[10] Y. Zhu, W. Hinds, S. Kim, S. Shen and C. Sioutas, "Study of ultrafine particles near a major highway with heavyduty diesel traffic," Atmospheric Environment, vol. 36, no. 27, pp. 4323-4335, 2002.

[11] Z. Yao, H.Wei, H. Perugul, H. Liu and Z. Le, "Sensitivity analysis of project level MOVES running emission rates for light and heavy duty vehicles," Journal of Traffic and Transportation Engineering, vol. 1, no. 2, pp. 81-96, 2014.

[12] G. Amirjamshidi and M. J. Roorda, "Development of simulated driving cycles for light, medium, and heavy duty trucks: Case of the Toronto Waterfront Area," Transportation Research Part D: Transport and Environment, vol. 34, pp. 255-266, 2015. 